\title{
Análisis de la imagen corporal y sus estereotipos en la cartelería de actividades para fomentar el uso de la bicicleta en España
}

\author{
David CERRO HERRERO
}

Universidad de Extremadura

(Recibido, 7 de Junio de 2018; Aceptado, 11 de Julio de 2018)

RESUMEN: El fomento del uso de la bicicleta se enmarca dentro de las prioridades expuestas por la Organización Mundial de la Salud (OMS). En este sentido desde el año 2004 la OMS invita a los gobiernos nacionales y locales para la implementación de políticas que faciliten el acceso a la posibilidad de desplazarse andando y en bicicleta. En esta línea cada vez son más las administraciones que ponen en marcha campañas de promoción del uso de la bicicleta y la realización de "Días de la bicicleta". El objetivo del presente estudio es analizar el uso de la imagen corporal en los carteles de promoción de dichas campañas y eventos puntuales en España, para estudiar si se promueven algún estereotipo en cuanto al uso de la bicicleta.

En el estudio se ha contado con una muestra de 53 carteles de eventos y campañas relacionados con el fomento del uso de la bicicleta en España en el año 2017. El estudio es de tipo empírico, descriptivo y utiliza el análisis de contenido como técnica central de la investigación.

Los carteles de promoción del uso de la bicicleta utilizan la imagen corporal en el 60,4\% de los carteles. En el caso de utilizar imagen corporal predominan las imágenes familiares $(24,6 \%)$, mujeres $(13,2 \%)$, hombres $(9,4 \%)$ y niños/as $(15,1 \%)$. En cuanto al somatotipo predominante entre los participantes destaca el ectomorfo en el $100 \%$ de imágenes corporales utilizadas en los carteles. El modelo predominante en la cartelería es la bicicleta de paseo $(45,3 \%)$.

Palabras clave: bicicleta, imágenes, estereotipos, corporal.

\section{Analysis of the body image and its stereotypes in the activity posters to promote bicycles} use of bicycles in Spain

\begin{abstract}
The promotion of the use of bicycles is part of the priorities set out by the World Health Organization (WHO). In this regard, since 2004, WHO has been inviting national and local governments to implement policies that facilitate access to the possibility of walking and walking. In this line, more and more administrations are launching campaigns to promote the use of bicycles and the realization of "Bicycle Days". The objective of the present study is to analyze the use of body image in the promotional posters of these campaigns and specific events in Spain, to study if any stereotypes are promoted regarding the use of bicycles.

In the study there was a sample of 53 posters of events and campaigns related to the promotion of the use of bicycles in Spain in 2017. The study is empirical, descriptive and uses content analysis as the central technique of the investigation.
\end{abstract}


Posters promoting the use of bicycles use body image in $60.4 \%$ of the posters. In the case of using body image, family images predominate $(24.6 \%)$, women $(13.2 \%)$, men $(9.4 \%)$ and children $(15.1 \%)$. Regarding the predominant somatotype among the participants, the ectomorph stands out in $100 \%$ of the body images used in the posters. The predominant model in the signage is the walking bicycle $(45.3 \%)$.

Keywords: bicycle, images, stereotypes, body.

Correspondencia: David Cerro Herrero, Departamento Didáctica de la expresión musical, plástica y corporal, Universidad de Extremadura, Facultad de Formación del Profesorado Av. Universidad S/N Cáceres C.P. 10001 E-mail: davidcerro@unex.es

\section{Introducción}

El fomento del uso de la bicicleta se enmarca dentro de las prioridades expuestas por la Organización Mundial de la Salud (OMS). En este sentido desde el año 2004 la OMS invita a los gobiernos nacionales y locales para la implementación de políticas que faciliten el acceso a la posibilidad de desplazarse andando y caminando, así como el uso de medios de transporte no motorizado, como por ejemplo la bicicleta.

La Unión Europea también ha mostrado interés por el concepto de Movilidad Urbana Sostenible, en este sentido la Comisión de las Comunidades Europeas (CCE) en 2007 publicó el "Libro Verde Hacia una Nueva Cultura de la Movilidad Urbana" y en 2010 se presentó el "Plan de Acción de Movilidad Urbana".

En España también se han desarrollado documentos para fomentar la movilidad sostenible. El Libro Verde del Medio Ambiente Urbano (Ministerio de Medio Ambiente, 2007) se marcan directrices para las administraciones españolas, entre ellas destaca la referida al "protagonismo de los modos de transporte sostenibles, relevancia y oportunidad para el peatón, la bicicleta y el transporte colectivo".

El Bicicleta Club de Cataluña (2011) realiza para la Dirección General de Tráfico de España un estudio para fomentar el uso de la bicicleta en los municipios. Las estrategias que deben seguir las ciudades según este estudio son:

- Mejorar la seguridad vial de los ciclistas

- Garantizar la intermodalidad de la bicicleta

- Creación de una red básica de vías ciclistas

- Lucha contra los robos de bicicletas

- Medidas de ámbito legislativo

- Financiar infraestructuras viarias para bicicletas

- Promoción de la investigación y asesoría sobre la movilidad en bicicleta

- Campañas de promoción del uso de la bicicleta

- Medidas ejemplarizantes para mejorar la imagen de la bicicleta

- Ayudas a las entidades ciudadanas que trabajan a favor de la bicicleta

Debido a la gran relevancia que está tomando la movilidad sostenible y las recomendaciones desde diferentes organismos nacionales e internacionales, la mayoría de municipios intentan implementar alguna medida para el fomento del uso de la bicicleta. Dado 
el alto coste de algunas de las estrategias y su largo plazo de ejecución, son muchos los municipios que optan por el desarrollo de campañas de promoción del uso de la bicicleta. En esta línea cada vez son más las administraciones que ponen en marcha campañas de promoción del uso de la bicicleta y la realización de "Días de la bicicleta".

Las imágenes tienen un gran poder en todos los ámbitos de la vida, de ahí la expresión "el aire que respiramos se compone de oxígeno, hidrógeno e imágenes" (Luengo y Blázquez, 2004). Las imágenes se perciben como un reflejo objetivo de la realidad, pero éstas no son neutras, sino que están mediatizadas y contribuyen a la construcción subjetiva de la realidad. La falta de reflexión sobre las imágenes presentes en los libros de texto puede hacer que reproduzcan estereotipos sin cuestionar su pertinencia (Palomares y Cao, 2013). De igual modo que las imágenes presentes en libros, revistas influyen en nuestra percepción de la realidad, esto sucede con las imágenes de promoción de actividades físico deportivas, como es el caso del uso de la bicicleta. Hasta ahora no se ha estudiado, ni prestado excesiva atención al uso que se hace de las imágenes en las herramientas utilizadas para la promoción del uso de la bicicleta.

El objetivo del presente estudio es analizar el uso de la imagen corporal en los carteles de promoción de dichas campañas y eventos puntuales en España, para estudiar si se promueven algún estereotipo en cuanto al uso de la bicicleta.

\section{Método}

El estudio llevado a cabo es de tipo empírico, descriptivo y utiliza el análisis de contenido como técnica principal de la investigación. Es un diseño no experimental seccional (Sierra, 1993) y vertical o intensivo (Piñuel, 2002). Se realiza un análisis de frecuencias, concretamente, de distribución de tipo estadístico. La unidad de muestreo son las fotografías utilizadas en los carteles que se utilizan para promocionar actividades e fomento del uso de la bicicleta, tanto campañas a nivel local como eventos del tipo "día de la bicicleta". Se utiliza como muestra los carteles localizados en Google cerrando la búsqueda a imágenes del año 2017 encontradas bajo las búsquedas "Campaña municipal bicicleta" y "día de la bicicleta", centrando la búsqueda en España. La muestra final utilizada está compuesta por 53 carteles de eventos y campañas relacionados con el fomento del uso de la bicicleta en España en el año 2017 , de los cuales $15,1 \%$ son de campañas (8) y $84,9 \%$ son de eventos de "día de la bicicleta" (45).

Para elaborar el sistema de categorías para el análisis de las imágenes se siguieron los siguientes pasos: 1. Elaboración de ficha inicial y prueba piloto de pertinencia de la "ficha de análisis para la imagen fija publicitaria" (López, 2005); 2. Adaptación de la ficha inicial; 3. Segunda prueba piloto; 4 . Consulta a expertos; 5 . Reelaboración en base a la consulta a expertos; 6 . Segunda consulta a expertos y 7 . Triangulación con tres observadores.

El sistema de categorías utilizado como instrumento para el análisis de las imágenes se centra en dos dimensiones: el cuerpo (con las categorías sexo, edad y somatotipo) y elementos ciclistas (con las categorías tipo de bicicleta, casco, indumentaria y tipo de uso). 


\section{Resultados}

Los carteles de promoción del uso de la bicicleta utilizan la imagen corporal en el 60,4\% de los carteles, siendo solo un $29,6 \%$ los que utilizan imágenes de bicicletas u otros elementos relacionados sin incluir a personas. En el caso de utilizar imagen corporal predominan las imágenes familiares $(24,6 \%)$, mujeres $(13,2 \%)$, hombre $(9,4 \%)$ y niños/as $(15,1 \%)$.

Figura 1: Tipos de imágenes utilizadas en los carteles de promoción del uso de la bicicleta

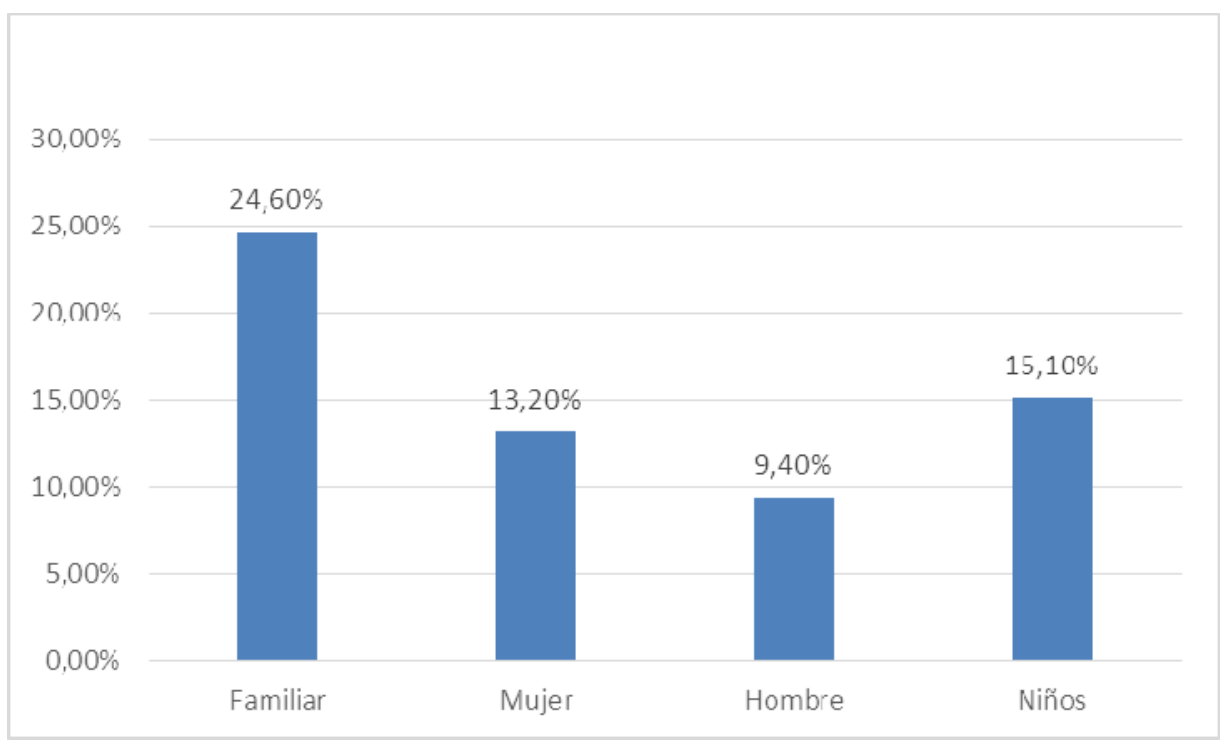

En cuanto al somatotipo predominante entre los participantes destaca el ectomorfo en el $100 \%$ de imágenes corporales utilizadas en los carteles. El modelo predominante en la cartelería es la bicicleta de paseo (45,3\%), seguida de la bicicleta de montaña $32,1 \%$, y en menor medida bicicleta de carretera $(3,8 \%)$, bicicleta fixie $1,9 \%$ y bicicleta infantil $(1,9 \%)$.

Figura 2: Tipo de bicicleta presente en los carteles de promoción del uso de la bicicleta

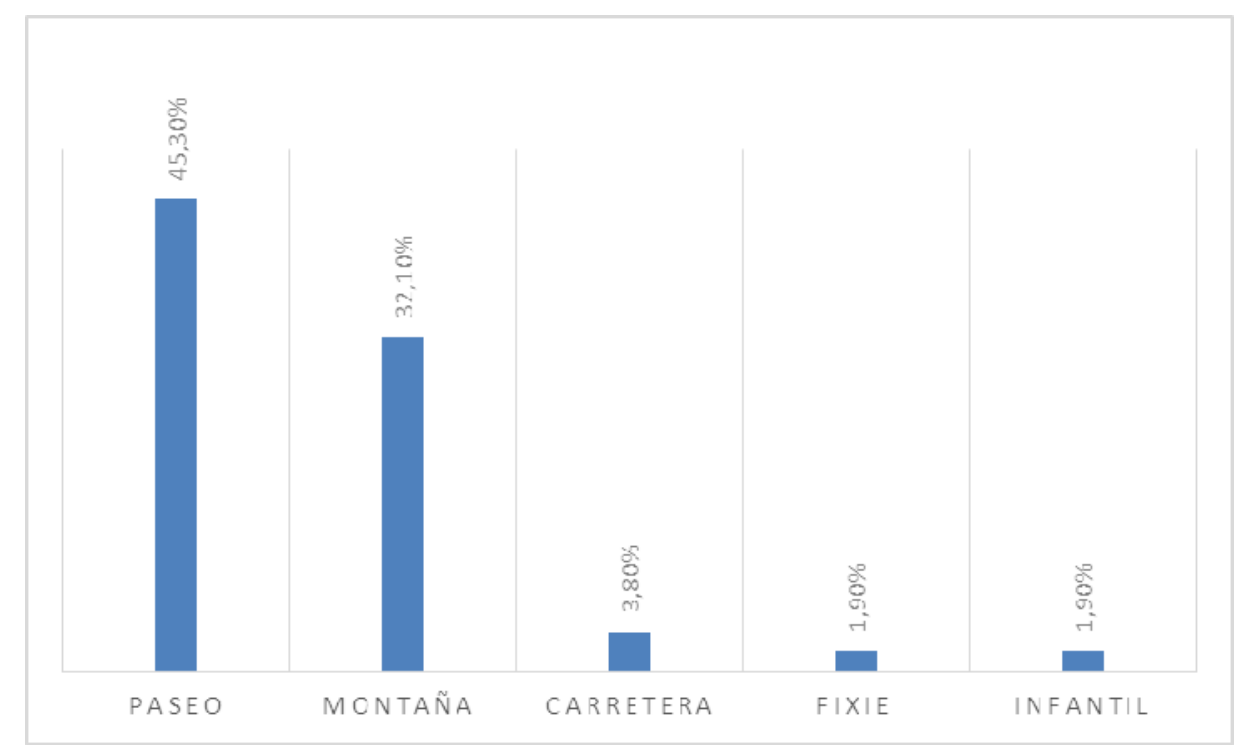


El uso del casco es predominante en la mayoría de carteles $(60,6 \%)$. En cuanto a la indumentaria predominan los usuarios con ropa de calle $(51,5 \%)$, con ropa deportiva $(21,2 \%)$ y con vestimenta ciclista $(9,1 \%)$.

Figura 3: Tipo de vestimenta de los protagonistas de la cartelería de fomento del uso de la bicicleta

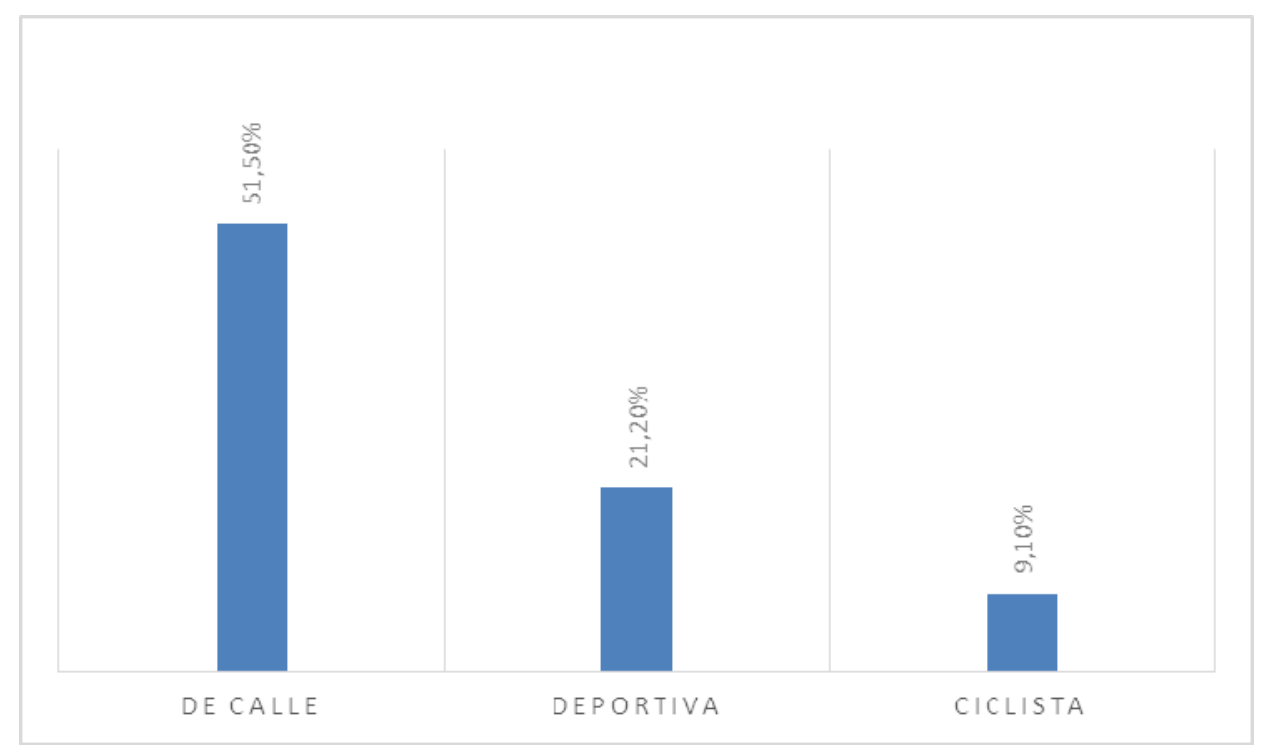

Si se analiza la edad de los participantes predominan los adultos $(37,8 \%)$ ante los niños (34 \%) y en menor medida los jóvenes $(5,6 \%)$.

Figura 4: Edad de los protagonistas de la cartelería de fomento del uso de la bicicleta

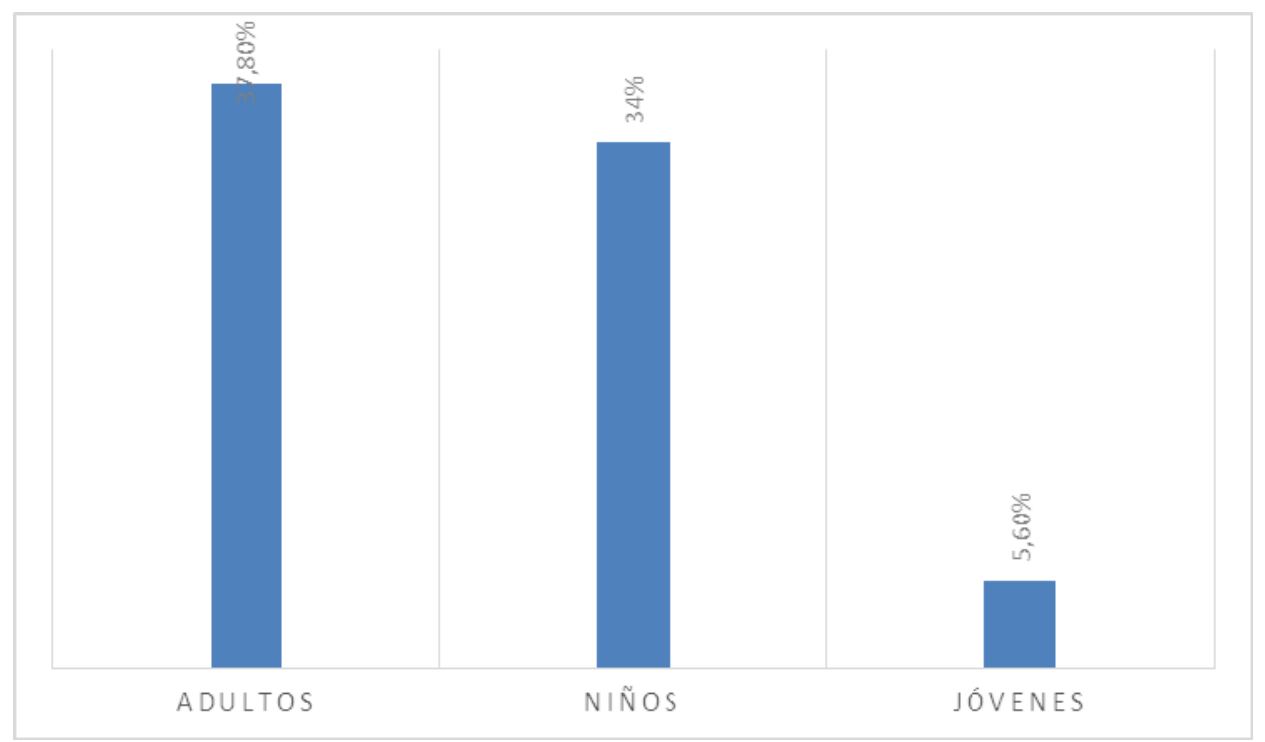

El tipo de uso que se aprecia por parte de los protagonistas es principalmente lúdico o de paseo $(51,5 \%)$, frente al uso como medio de desplazamiento urbano $(18,1 \%)$ y finalmente el uso deportivo $(12,1 \%)$. 


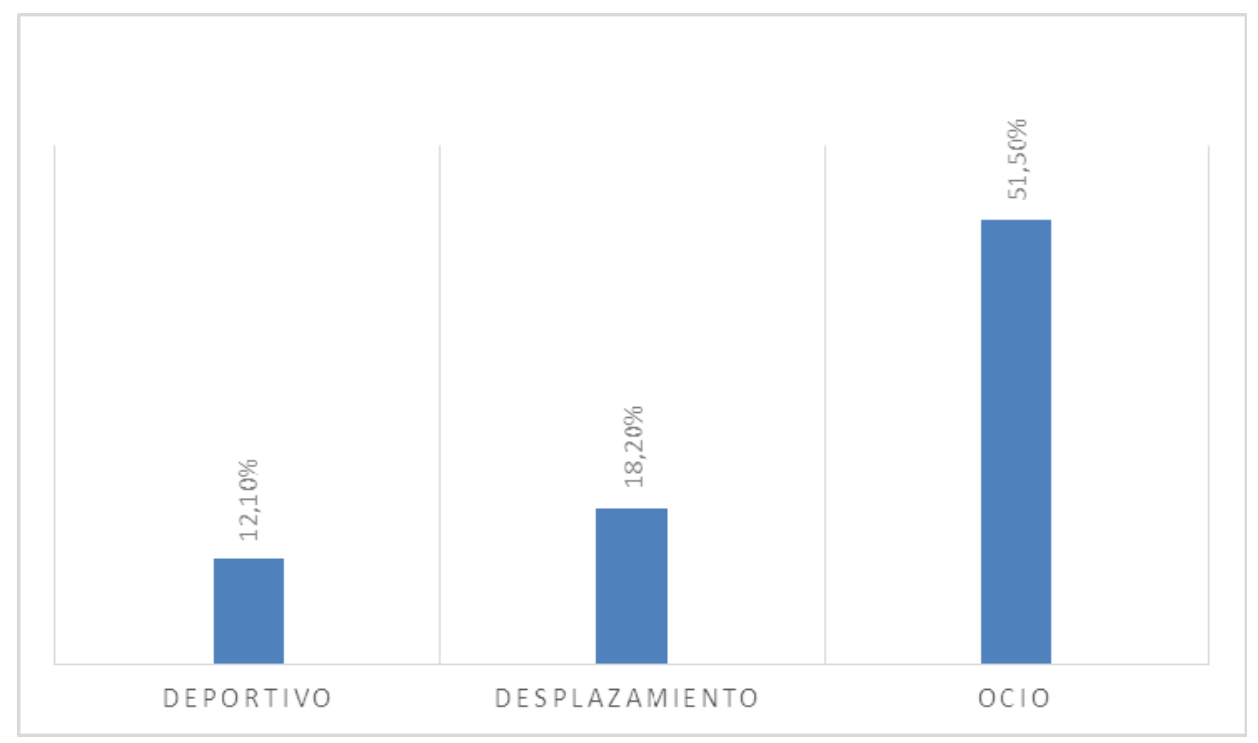

\section{Discusión}

Los resultados obtenidos no muestran desigualdad entre el uso de imágenes de hombres y mujeres. Lo cual difiere de estudios previos en otros ámbitos de la actividad física como Parra (2002), González (2005) y Tabóas y Rey (2007) en sus estudios sobre libros de texto. Es interesante que a pesar de que aun en muchos ámbitos del deporte y la actividad física se sigue primando la imagen del hombre, en el uso de la bicicleta se aprecia una visión más igualitaria, al menos en el ámbito de promoción del uso.

En cuanto al somatotipo de los sujetos que protagonizan la cartelería se ha encontrado el uso exclusivo del ectomorfo. Tabóas y Rey (2007) en su estudio sobre libros de texto de educación física encontraron mayor variedad, primando los somatotipos combinados. En el mismo estudio tan solo se encontró un sujeto endomorfo en los libros de texto de 242 encontrados. Por tanto, es significativo la exclusión de los sujetos con sobrepeso de las imágenes que pretenden fomentar la actividad física, más en un país como España donde los índices de obesidad son muy elevados. En España, de acuerdo con el Informe Anual de 2016 del Sistema Nacional de Salud, la obesidad afecta al $16,9 \%$ de la población de 15 y más años (17,1\% hombres y $16,7 \%$ mujeres).

En cuanto a la edad de los protagonistas de la cartelería las administraciones públicas se centran en adultos y niños, dejando a una participación muy minoritaria a los jóvenes. Es contradictoria esta tendencia ante el gran problema que supone el abandono de la práctica deportiva en los jóvenes. Son muchos los estudios que han puesto de manifiesto esta problemática (Boiché y Sarrazin, 2009; Cervello, 1999; Molinero, 2006). Varios estudios encuentran que los niveles de práctica deportiva suelen encontrar su punto más bajo en la etapa de la educación secundaria (Currie, et al., 2004; Pérez y Acuña, 2002; Valverde, 2010), por ello sería fundamental visibilizar en las acciones de promoción a estas edades como principales destinatarios de las campañas de promoción del uso de la bicicleta. 
Es de destacar que la imagen de bicicleta prioritaria para las administraciones sea la bicicleta de paseo, cuando los datos de ventas de bicicletas (AMBE, 2017) marcan claramente que la bicicleta más vendida en España es la de montaña (44\%). Esta tendencia en la cartelería puede limitar la participación al entender los ciudadanos que la actividad no va orientada hacia su bicicleta y por tanto no acudir a las actividades.

El uso del casco es predominante en la mayoría de carteles $(60,6 \%)$. Son contradictorios los estudios previos sobre la importancia de fomentar o no el uso del casco. A favor del uso del casco están los estudios que estiman que el uso de casco podría disminuir un $88 \%$ las lesiones craneoencefálicas y un 65\% las lesiones faciales (Macpherson, y Spinks, 2008). Sin embargo, otros estudios muestran como el fomento del uso del casco tiende a la disminución del uso de la bicicleta o favorecer conductas de riesgo entre los ciclistas (Clarke, 2011; Robinson, 2006).

El presente estudio tiene como principal limitación la selección de la muestra, es necesario ampliar la muestra con nuevos carteles de más ciudades y municipios, incluso ampliando a otros países.

Las líneas de futuro para continuar con esta temática de investigación son la inclusión de nuevas posibles categorías como la raza de los protagonistas. También se debe avanzar en el estudio de la percepción por parte de los usuarios de las campañas de promoción. Por último, sería interesante el desarrollo de manuales o recomendaciones para municipios, con el fin de lograr que las campañas de promoción del uso de la bicicleta sean lo más integradoras y efectivas posibles, logrando la movilización de la ciudadanía hacia el uso de la bicicleta. Es fundamental la inclusión de personas de otras razas, personas con discapacidad y personas con obesidad en las campañas de promoción del uso de la bicicleta, si realmente se quiere llegar a toda la población.

\section{Referencias}

AMBE (2017). El sector de la Bicicleta en Cifras 2016. Consulta 15 abril de 2018. Disponible en: http://asociacionambe.es/wp-content/uploads/2014/12/Presentaci\%C3\%B3n-Notade-Prensa-2016-1.pdf

Bicicleta Club De Cataluña (2011). Estudio sobre las Estrategias de promoción de la bicicleta como medio de transporte en las ciudades españolas. DGT. Consulta: 12 abril de 2018. Disponible en: http://www.dgt.es/Galerias/seguridad-vial/investigacion/estudios-einformes/INFORME-ESTUDIO-SOBRE-LAS-ESTRATEGIAS-DE-PROMOCIONDE-LA-BICICLETA-9.pdf

Boiché, J., y Sarrazin, P. (2009). Proximal and distal factors associated with dropout versus maintained participation in organized sport. Journal of Sport Science and Medicine, $8,9-16$.

Clarke, C. F. (2012). Evaluation of New Zealand's bicycle helmet law. The New Zealand Medical Journal (Online), 125(1349).

Cervelló, E. M., y Santos-Rosa, F. J. (2000). Motivación en las clases de educación física: un estudio de la perspectiva de las metas de logro en el contextoeducativo. Revista de Psicología del Deporte, 9, 51-70. 
Comisión de las Comunidades Europeas (2007). Libro verde hacia una nueva cultura de la movilidad urbana [en línea]. Consulta: 11 de abril de 2018. Disponible en: $\mathrm{http}: / /$ ec.europa.eu/transport/clean/green_paper_urban_transport/doc/2007_09_25_gp_ur ban_mobility_es.pdf

Currie, C., Roberts, C., Morgan, A., Smith, R., Settertobulte, W., Samdal, O. y Barnekow Rasmussen, V. (2004). Young people's health in context. Health Behaviour in School-aged

Children (HBSC) study: international report from the 2001/2002survey.World Health Organization

González Pascual, M. (2005). ¿Tienen sexo los contenidos de la Educación Física Escolar? Transmisión de estereotipos de sexo a través de los libros de texto en la etapa de secundaria. Revista Internacional de Medicina y Ciencias de la Actividad Física y del Deporte, 5(18).

López Villar, C. (2005). Las imágenes fijas del cuerpo relacionadas con la actividad fisica y el deporte. Análisis de su uso en la publicidad de revistas. Tesis doctoral. Pontevedra: Universidad de Vigo.

Luengo González, M.R. y Blázquez Entonado, F. (2004). Género y Libros de Texto. Un estudio de estereotipos en las imágenes. Badajoz: Junta de Extremaduar. Instituto de la Mujer de Extremadura.

Macpherson, A., \& Spinks, A. (2008). Bicycle helmet legislation for the uptake of helmet use and prevention of head injuries. Cochrane Review, 16(3), CD005401.

Ministerio de Medio Ambiente (2007). Libro verde de medio ambiente urbano. Tomo I [en línea]. Consulta: 1 de abril de 2018. Disponible en: https://issuu.com/ecourbano/docs/libro_verde_de_medio_ambiente_urbano_partes_1_2_y Molinero, O., Salguero, A., Tuero, C., Álvarez, E., y Márquez, S. (2006). Dropout reasons in Young Spanish athletes: relationship to Gender, type of sport and level of competition. Journal of sport Behavior, 29(3), 255-269.

Palomares, A. G., y Cao, A. R. (2013). Cultura corporal y estereotipos en las imágenes de libros de texto de educación física publicados bajo el periodo de la Ley Orgánica de Educación (LOE). Ágora para la Educación Física y el Deporte, 15(1), 1-19.

Parra, J. (2002). El sexismo en los libros de texto de Educación Física en segundo ciclo de ESO y Bachillerato. Lecturas: Educar en Castilla la Mancha. Recuperado de http://www. jccm. es/educación/educar/num_16/opinion. html.

Pérez, J. A., y Acuña, A. (2002). La competición en el ámbito escolar: un programa de intervención social. Alicante: Universidad de Alicante.

Piñuel Raigada, J. L. (2002). Epistemología, metodo-logía y técnicas del análisis de contenido. Estudios de Sociolingüística, 3(1), 1-42.

Robinson, D. L. (2006). No clear evidence from countries that have enforced the wearing of helmets. BMJ: British Medical Journal, 332(7543), 722.

Sierra Bravo, R. (1993). Tesis doctorales y trabajos de investigación cientifica. Madrid: Paraninfo.

S. S. e I. Ministerio de Sanidad (2017), "Informe Anual del Sistema Nacional de Salud," Madrid. 
Táboas País, M. I., \& Rey Cao, A. I. (2007). El cuerpo en las imágenes de los libros de texto de educación física: análisis de dos editoriales. Kronos: Revista Universitaria de la Educación Física y el Deporte, 11, 10-15.

Valverde, J. (2010). Valoración y niveles de Actividad Física habitual en escolares. Sevilla: Wanceulen Editorial Deportiva.

World Health Organization. (2004). Estrategia mundial sobre régimen alimentario, actividad física y salud. 